\title{
Apolipoprotein E and Change in Episodic Memory in Blacks and Whites
}

\author{
L.L. Barnes ${ }^{a-c}$ Z. Arvanitakis ${ }^{a, b} \quad$ L. Yu ${ }^{a, b} \quad$ J. Kelly ${ }^{d} \quad$ P.L. De Jager ${ }^{e-g}$ \\ D.A. Bennett ${ }^{a}, b$
}

${ }^{a}$ Rush Alzheimer's Disease Center, and Departments of b Neurological Sciences and 'Behavioral Sciences, Rush University Medical Center, Chicago, III., 'dDepartment of Internal Medicine, University of New Mexico School of Medicine, Albuquerque, N. Mex., e'Brigham and Women's Hospital, and fDepartment of Genetics, Harvard Medical School, Boston, Mass., and ${ }^{9}$ Broad Institute, Massachusetts Institute of Technology, Cambridge, Mass., USA

\section{Key Words}

Apolipoprotein E • Episodic memory $\cdot$ Cognitive decline

\begin{abstract}
Background: Apolipoprotein E (APOE) $\varepsilon 4$ is related to faster decline in episodic memory in Whites, but the relation is unknown in Blacks. The purpose of this study was to determine whether $\varepsilon 4$ has a selective effect on decline in episodic memory in Blacks. Methods: Data are from two cohort studies with similar design. The sample consisted of 1,211 participants $[28.4 \%$ Blacks, mean age $=78.6$ years $(S D=7.4)$, education $=14.7$ years $(S D=3.1)$ ] without dementia at baseline, who underwent annual clinical evaluations for up to 6 years. Summary measures of 5 cognitive abilities were derived from 18 neuropsychological tests. Results: In mixed models that controlled for age, sex, education, and race, possession of $\varepsilon 4$ (present in $32.9 \%$ of Blacks and $21.0 \%$ of Whites, $p<$ 0.001 ) was related to faster decline in episodic memory and 4 other cognitive abilities (all $p$ values $<0.01$ ). In separate models that examined the interaction of race and $\varepsilon 4$ on decline, there was no significant difference between Blacks and Whites in the effect of $\varepsilon 4$ on decline in episodic memory, perceptual speed, or visuospatial ability. By contrast, the effect of $\varepsilon 4$ differed for semantic memory and working memory. Results were similar after adjusting for vascular
\end{abstract}

conditions. Conclusions: The results suggest that APOE $\varepsilon 4$ is related to a faster rate of decline in episodic memory in Blacks similar to Whites. In addition, there were racial differences in the effect of $\varepsilon 4$ in other cognitive abilities such that the $\varepsilon 4$ allele was related to faster decline in semantic memory and working memory for Whites but not for Blacks.

Copyright $\odot 2013$ S. Karger AG, Basel

\section{Introduction}

Apolipoprotein E (APOE) is a cholesterol transport plasma protein that has 3 different alleles $(\varepsilon 2, \varepsilon 3$, and $\varepsilon 4)$ on chromosome 19. The 3 alleles code for 3 different $A P O E$ isoforms (apoE2, apoE3, and apoE4), which results in 6 potential genotypes $(\varepsilon 2 / 2, \varepsilon 2 / 3, \varepsilon 2 / 4, \varepsilon 3 / 3, \varepsilon 3 / 4$, and $\varepsilon 4 / 4)$. The $\varepsilon 4$ allele has been shown to be associated with many adverse health outcomes [1,2], including Alzheimer's disease $(\mathrm{AD})$ and cognitive decline [3-5].

There is considerable ethnic/racial variation in the $A P O E$ genotype frequency with Blacks having a higher frequency of $\varepsilon 4$ compared with Whites [6]. Despite the higher frequency among Blacks, however, little is known about its relationship to cognition. Most studies that include Blacks have focused on $\varepsilon 4$ as a risk factor for $\mathrm{AD}$, and the findings have been mixed. Of 13 studies that in-

\section{KARGER}

Fax +4161306 1234

E-Mail karger@karger.ch

www.karger.com (c) 2013 S. Karger AG, Basel

0251-5350/13/0403-0211\$38.00/0

Accessible online at:

www.karger.com/ned
Lisa L. Barnes, PhD

Rush Alzheimer's Disease Center, Rush University Medical Center

600 S. Paulina, Suite 1038

Chicago, IL 60612 (USA)

E-Maillbarnes1@ rush.edu 
cluded Blacks in their sample and evaluated the effect of $A P O E \varepsilon 4$ on $\mathrm{AD}, 6$ showed an increased risk of $\mathrm{AD}$ for Blacks with the $\varepsilon 4$ allele, including a recent genome-wide association study [5,7-11]. Five studies indicated that the $\varepsilon 4$ allele was not related to an increased risk of $\mathrm{AD}$ in Blacks [6, 12-15]. There were 2 studies that showed risk of $\mathrm{AD}$ among $\varepsilon 4$ carriers depended on the variant of $\varepsilon 4$ status $[16,17]$. That is, homozygotes $(\varepsilon 4 / \varepsilon 4)$ had an increased risk but not heterozygotes $(\varepsilon 3 / \varepsilon 4)$. Findings with cognition as the outcome demonstrate a similar pattern, although a slightly larger proportion of studies report a positive association between $A P O E \varepsilon 4$ and cognition or cognitive decline among Blacks. There were 4 studies that showed that the $\varepsilon 4$ allele was related to a faster rate of cognitive decline among Blacks in longitudinal studies [18-20] and lower performance on cognitive tests in cross-sectional studies [21]. In contrast, 2 studies showed that the $\varepsilon 4$ allele was not associated with cognitive decline in middle-aged Blacks [22] in a longitudinal study or with performance on cognitive tests in a cross-sectional study [23]. One study [24] had mixed results for crosssectional and longitudinal findings. They found that Blacks and Whites with $\varepsilon 4$ had lower cognition scores in cross-sectional analyses, but in longitudinal analyses, only Whites with $\varepsilon 4$ had a faster rate of cognitive decline. Compared to the well-established literature on APOE $\varepsilon 4$ in Whites, it appears that the effect of $\varepsilon 4$ on cognition in Blacks is much more variable. Further, most of these studies did not explicitly test for racial differences in the effect of $\varepsilon 4$ on $\mathrm{AD}$ or cognition. In fact, we are aware of only 3 studies that have specifically examined the effect of $\varepsilon 4$ and cognitive decline in Blacks, and these results were also mixed as noted, with 1 study finding an association in Whites but not Blacks [24], and 2 other studies from the same cohort reporting that the $\varepsilon 4$ allele is related to decline in both Blacks and Whites $[19,20]$.

There is emerging evidence in Whites that the $\varepsilon 4$ allele has a relatively selective effect on episodic memory [2527]. It is possible that the $A P O E$ findings in Blacks have been mixed because studies have relied only on brief screening measures of cognition [19,20,24], potentially obscuring any relatively specific effect of $A P O E$ on episodic memory. Given that Blacks may have an increased risk of AD [28], of which impairment in episodic memory is an early defining feature, and they have a higher frequency of the $\varepsilon 4$ allele, we hypothesized that the $\varepsilon 4$ allele would have a selective effect on decline in episodic memory in Blacks similar to Whites. We also examined its relation to decline in 4 other cognitive abilities and the extent to which the association of allele status with cogni- tive decline varied by race. We used data from the Minority Aging Research Study [29] and the Rush Memory and Aging Project [30], 2 community-based cohort studies of risk factors for cognitive decline. Participants were 65 years and older and free of known dementia at the time of enrollment. They underwent uniform annual clinical evaluations, including detailed cognitive function testing and ascertainment of $A P O E$ status at baseline. Composite measures of episodic memory, semantic memory, working memory, perceptual speed, and visuospatial ability were the main outcomes.

\section{Methods}

Subjects

Participants were from the Minority Aging Research Study and the Rush Memory and Aging Project. The Minority Aging Research Study is a longitudinal study of risk factors for cognitive decline in older Blacks [29]. The Rush Memory and Aging Project is a longitudinal, clinical-pathologic study of risk factors for common chronic conditions of old age [30]. Participants from both cohorts are recruited using identical recruitment strategies from similar geographical regions. Further, the studies have very similar data collection and operational methods, which facilitates analyses of data from the combined cohorts [31]. Both studies were approved by the Institutional Review Board of Rush University Medical Center.

Minority Aging Research Study

The participants were older community-dwelling Blacks. Eligibility required age of 65 years or older, absence of known dementia, self-report of Black race, and consent to annual clinical evaluations and neuropsychological testing. Subjects were recruited from various community-based organizations, churches, and senior subsidized housing facilities in and around the Chicago metropolitan area. The study has a rolling admission, and more than 400 persons have completed a uniform structured baseline clinical evaluation between August 2004 and July 2011.

\section{Rush Memory and Aging Project}

Participants were older persons without known dementia who agreed to annual clinical evaluations and signed an informed consent and an Anatomical Gift Act donating his/her brain, spinal cord, and selected nerve and muscle to Rush investigators at the time of death. Participants were mainly recruited from about 40 retirement communities and senior housing facilities across counties in northeastern Illinois. The study involves detailed annual clinical evaluations and organ donation at death. More than 1,400 persons have completed a uniform structured baseline clinical evaluation between October 1997 and July 2011.

\section{Clinical Evaluation}

Eligibility for inclusion in the current analyses required that dementia be absent at baseline. Clinical classification of dementia was based on a uniform, structured clinical evaluation that included a medical history, neurological examination, and assess- 
ment of cognitive function (see below). On the basis of this evaluation, a clinician classified persons with respect to dementia using the criteria of the joint working group of the National Institute of Neurological and Communicative Disorders and Stroke and the Alzheimer's Disease and Related Disorders Association [32]. These criteria require a history of cognitive decline and impairment in at least 2 domains of cognitive function. Of 1,848 persons from the 2 cohorts who were eligible for this study, 74 were excluded because of dementia at baseline, and 101 were excluded who reported Hispanic ethnicity (86 persons) or a racial background other than Black or White (15 persons). Of the remaining $1,673,377$ did not have a valid genotype and 85 did not have at least 2 valid global cognition scores to measure change over time. Of the remaining, 1,211 (345 Black, 866 White) persons are included in the analytic sample.

\section{Assessment of Cognitive Function}

A battery of 19 cognitive function tests was administered in a 1-hour session. One test, the Mini-Mental State Examination (MMSE), was used to describe the overall cognitive functioning of the cohorts, but not in analyses. The remaining 18 performance-based tests assessed the level of and change in episodic memory, semantic memory, working memory, perceptual speed, and visuospatial abilities. Details of the cognitive function tests have been reported previously [33]. There were 7 tests of episodic memory (immediate and delayed story recall of story A from the Logical Memory subtest of the WMS-R [34] and of the East Boston Story $[35,36]$ and Word List Memory, Word List Recall, and Word List Recognition from the procedures established by CERAD [37]); 2 tests of semantic memory (a 15-item version [37] of the Boston Naming Test $[37,38]$ and Semantic Verbal Fluency from CERAD [36, 37]); 3 tests of working memory (Digit Span Forward and Digit Span Backward from the Wechsler Memory Scale-Revised [34] and Digit Ordering [36, 39]); 4 measures of perceptual speed (Symbol Digit Modalities Test [40], Number Comparison [41], and 2 indices from a modified version of the Stroop Neuropsychological Screening Test, i.e. the number of color names correctly read aloud in $30 \mathrm{~s}$ minus the number of errors, and the number of colors correctly named in 30 s minus the number of errors [42]), and 2 tests of visuospatial ability (a 15-item version of Judgment of Line Orientation [43] and a 16-item version of Standard Progressive Matrices [44]).

Composites of two or more cognitive tests, based in part on the results of a previous factor analysis of these tests [33], were used in analyses. For each composite measure, raw scores on individual tests were converted to $\mathrm{Z}$ scores using the mean and SD at baseline for the entire sample. The $\mathrm{Z}$ scores on the component tests were then averaged to yield the composite score, as previously described $[33,36]$.

\section{Assessment of Other Covariates}

Other covariates included in the statistical models were age at baseline, sex and education. Educational attainment was expressed as years of formal schooling completed, as reported by the participant. Because vascular conditions have been associated with cognitive function and the APOE polymorphism is an important modulator of plasma lipoprotein, premature atherosclerosis, and a higher incidence of clinical coronary heart disease $[45,46]$, participants were asked about vascular risk factors and conditions in the medical history and clinical evaluation. Com- posite measures of vascular risk factor burden (i.e., the number of 3 risk factors present - hypertension, smoking, and diabetes mellitus) and vascular disease burden (i.e., the number of 4 conditions present - claudication, stroke, congestive heart failure, and heart attack) were computed on the basis of self-report questions and medication inspection, as previously described [47].

\section{APOE Genotyping}

Blood was collected with acid citrate dextrose anticoagulant, stored at room temperature, and underwent lymphocyte separation within $24 \mathrm{~h}$ of collection. DNA was extracted from approximately 2-3 million cells, and genotyping was done by Agencourt Bioscience Corporation (Beverly, Mass., USA) utilizing highthroughput sequencing of codon 112 (position 3937) and codon 158 (position 4075) of exon 4 of the APOE gene on chromosome 19 , blinded to all clinical data, as previously described [48].

\section{Data Analysis}

For all analyses, participants with an $\varepsilon 2 / 4$ allele were excluded from analyses and the remaining participants were divided into three groups: those with an $\varepsilon 4$ allele (i.e., $\varepsilon 3 / 4$ and $\varepsilon 4 / 4$ ), those with an $\varepsilon 2$ allele (i.e., $\varepsilon 2 / 2$ and $\varepsilon 2 / 3$ ), and those with $\varepsilon 3 / 3$ (used as the reference). We first used tests and $\chi^{2}$ tests to analyze racial differences in demographic characteristics, overall cognition, and allele status. For the main analysis, we examined the association of allele status with change in 5 cognitive systems. We used linear mixed models to characterize individual paths of change in specific measures of cognitive function and to examine the relationship of allele status to initial level of cognitive function and annual rate of change [49]. The models characterize each person's individual intercept and slope with random effects. Each individual is assumed to follow the mean path of the group except for random effects, which cause the initial level of cognition to be higher or lower and the rate of change to be slower or faster. The primary model included: time from the baseline interview (in years), $\varepsilon 4, \varepsilon 4 \times$ time, $\varepsilon 2, \varepsilon 2 \times$ time, race, and race $\times$ time. All models also controlled for the potentially confounding effects of age, sex, and education. The term for time indicates the mean change in cognition per year in the reference group $(\varepsilon 3 / \varepsilon 3)$. The terms for $\varepsilon 4$ and its interaction with time test the relation of $\varepsilon 4$ to baseline level of cognitive function and annual rate of cognitive change in $\varepsilon 4$ carriers. Likewise, the terms for $\varepsilon 2$ and its interaction with time test the relation of $\varepsilon 2$ to baseline level of cognitive function and annual rate of cognitive change in $\varepsilon 2$ carriers. Because of the low frequency of persons with any $\varepsilon 2$, we only focus on the results for any $\varepsilon 4$ in the current analysis. The terms for race and its interactions with time and $\varepsilon 4$ status test racial differences in the effect of $\varepsilon 4$ on cognitive decline. Models stratified by race were subsequently conducted to confirm significant race interactions from the primary full models. These models were similar to the primary models except there were no terms for race included. We then conducted a series of secondary data analyses. First, we added control variables for vascular risk factor burden and vascular disease burden to the primary models to determine whether the effect of $A P O E$ on decline was independent of these healthrelated variables. Then, since the Memory and Aging Project began data collection in 1997 and has a longer follow-up time than the Minority Aging Research Study, we examined the association of allele status and cognitive decline in models restricted to a subsample of Memory and Aging Project participants matched on 


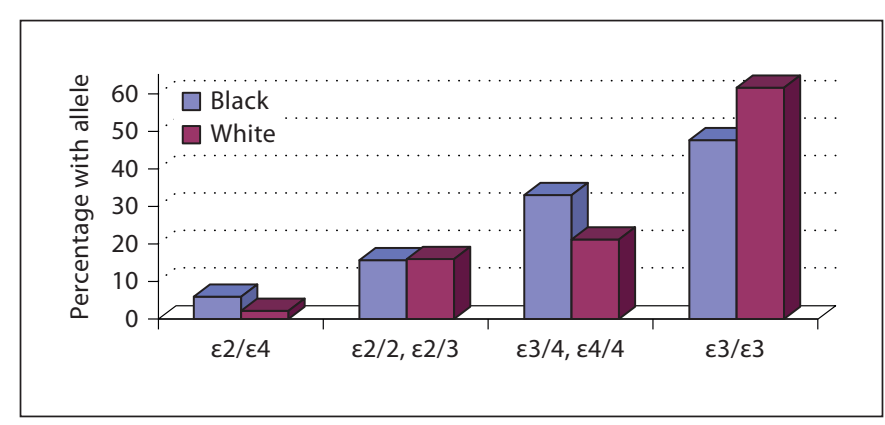

Fig. 1. Percentage of Blacks and Whites in the Minority Aging Research Study and the Memory and Aging Project with the different combinations of allele genotypes.

Table 1. Sample characteristics of 1,211 participants in the Minority Aging Research Study and the Memory and Aging Project

\begin{tabular}{lccc}
\hline Characteristic & $\begin{array}{l}\text { Blacks } \\
(\mathrm{n}=345)\end{array}$ & $\begin{array}{l}\text { Whites } \\
(\mathrm{n}=866)\end{array}$ & $\begin{array}{l}\mathrm{p} \\
\text { value }\end{array}$ \\
\hline Age, years & $72.8 \pm 6.0$ & $80.9 \pm 6.7$ & $<0.001$ \\
Education, years $_{\text {Number of women }}^{\mathrm{a}}$ & $14.7 \pm 3.5$ & $14.7 \pm 2.9$ & 0.94 \\
MMSE score $_{\text {Number with any }}$ 4 4 allele $^{\mathrm{a}}$ & $253(73.3)$ & $638(73.7)$ & 0.90 \\
Vascular risk factor score & $127 \pm 36.8$ & $27.9 \pm 2.1$ & 0.71 \\
Vascular disease score & $0.27 \pm 0.56$ & $0.33 \pm 0.61$ & 0.14 \\
\hline
\end{tabular}

Figures are means \pm SD or numbers with percentages in parentheses.

${ }^{\mathrm{a}} \chi^{2}$ test.

follow-up time. To do so, we first determined the longest followup time for participants in the Minority Aging Research Study (6.7 years) and included all of the Memory and Aging Project participants who fell within the same calendar window starting from their earliest enrollment date, resulting in a sample size of 557 Memory and Aging Project participants. All models were validated graphically and analytically. Programming was done in SAS [50].

\section{Results}

Table 1 compares the characteristics of participants from the two samples (Minority Aging Research Study and Memory and Aging Project) that were merged for the current study. The mean age of the merged sample was 78.6 years $(\mathrm{SD}=7.4)$, mean education was 14.7 years $(\mathrm{SD}=3.1)$, and the mean MMSE score was $27.9(\mathrm{SD}=2.0)$.
On average, Blacks were younger than Whites and had a higher number of vascular risk factors. Blacks were more likely to possess at least one $\varepsilon 4$ allele (table 1$)$, consistent with other published reports $[6,20,24]$. However, they were comparable to Whites in terms of educational attainment, vascular disease burden, sex composition, and overall cognitive functioning as measured by the MMSE, likely the result of similar recruitment strategies in overlapping catchment areas for the two studies.

The most frequent $A P O E$ pair of genotypes in both Blacks and Whites was $A P O E \varepsilon 3 / 3$, and $\varepsilon 2 / 2$ was the least frequent. The distribution of $A P O E$ genotypes in study participants was as follows: Blacks: $\varepsilon 2 / 2=3 ; \varepsilon 2 / 3=51$; $\varepsilon 2 / 4=20 ; \varepsilon 3 / 3=164 ; \varepsilon 3 / 4=94$, and $\varepsilon 4 / 4=13$; Whites: $\varepsilon 2 / 2=7 ; \varepsilon 2 / 3=130 ; \varepsilon 2 / 4=18 ; \varepsilon 3 / 3=533 ; \varepsilon 3 / 4=166$, and $\varepsilon 4 / 4=12$ (fig. 1).

\section{APOE $\varepsilon 4$ and Cognitive Decline}

The relation of the APOE $\varepsilon 4$ allele to cognitive decline in 5 cognitive abilities is summarized in table 2. To test the hypothesis of a selective effect of $\varepsilon 4$ on decline in episodic memory in Blacks, we conducted a mixed effects model in the merged sample (including participants from both the Minority Aging Research Study and the Memory and Aging Project) with episodic memory as the outcome measure. Subsequent models examined the effect of $\varepsilon 4$ on the other cognitive abilities in 4 other models. In these analyses, possession of at least one $\varepsilon 4$ allele was associated with faster decline in all 5 cognitive abilities. The 3 -way interaction of $\varepsilon 4$, race, and time on study for episodic memory was not significant (estimate $=0.028, \mathrm{SE}=$ $0.021, p=0.19$ ), suggesting that the effect of $\varepsilon 4$ on decline in episodic memory did not differ for Blacks and Whites. By contrast, there were significant 3-way interactions for decline in semantic memory and working memory, which indicated that $\varepsilon 4$ is related to a faster rate of decline in Whites, but not in Blacks. To illustrate this finding, results for episodic memory and working memory are shown in figure 2. APOE $\varepsilon 4$ is related to a faster rate of decline in episodic memory in both Blacks and Whites compared with persons without the $\varepsilon 4$ allele, and there is no difference in this effect for Blacks and Whites. By comparison, the results for working memory show a different pattern. The $\varepsilon 4$ allele is associated with a faster rate of decline in working memory for Whites compared to Whites without the $\varepsilon 4$ allele, but Blacks with and without $\varepsilon 4$ have the same rate of $\operatorname{cog}$ nitive decline in working memory. The same pattern was observed for semantic memory - the $\varepsilon 4$ was related to a faster rate of decline in Whites but not in Blacks. These results were largely con- 

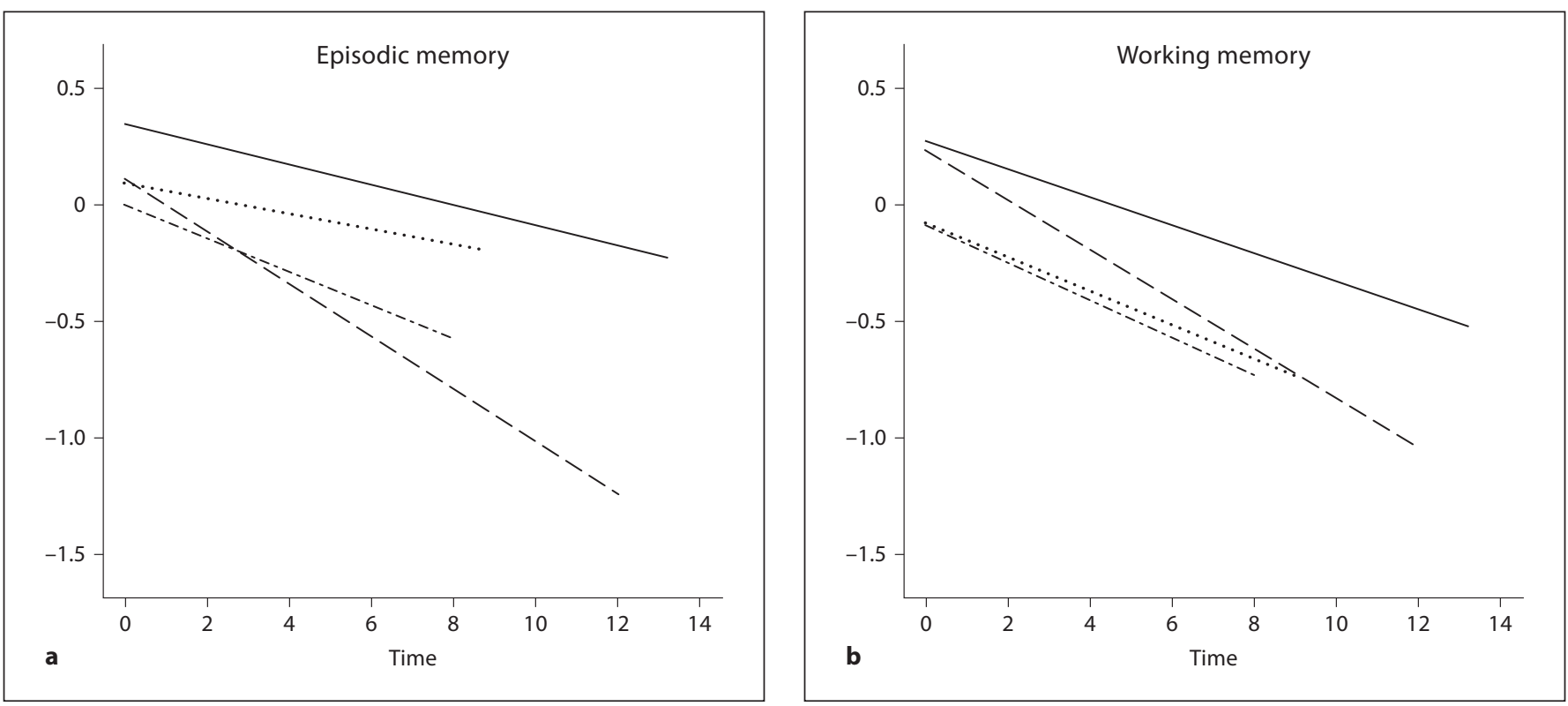

Fig. 2. Relation of APOE $\varepsilon 4$ to decline in episodic memory (a) and working memory (b) in Blacks and Whites. Blacks without $\varepsilon 4=$ dotted line; Whites without $\varepsilon 4=$ solid line; Blacks with $\varepsilon 4=$ dotted-dashed line; Whites with $\varepsilon 4=$ dashed line.

Table 2. Relation of $A P O E \varepsilon 4$ to level of and change in separate cognitive abilities

\begin{tabular}{|c|c|c|c|c|c|c|}
\hline & \multicolumn{3}{|l|}{ Model 1} & \multicolumn{3}{|l|}{ Model 2} \\
\hline & estimate & SE & $\mathrm{p}$ value & estimate & SE & $\mathrm{p}$ value \\
\hline \multicolumn{7}{|l|}{ Episodic memory } \\
\hline$\varepsilon 4$ & -0.156 & 0.042 & $<0.001$ & -0.200 & 0.051 & $<0.001$ \\
\hline$\varepsilon 4 \times$ time & -0.055 & 0.010 & $<0.001$ & -0.064 & 0.012 & $<0.001$ \\
\hline$\varepsilon 4 \times$ time $\times$ Black & & & & 0.028 & 0.021 & 0.19 \\
\hline \multicolumn{7}{|l|}{ Semantic memory } \\
\hline$\varepsilon 4$ & -0.034 & 0.044 & 0.44 & -0.059 & 0.054 & 0.27 \\
\hline$\varepsilon 4 \times$ time & -0.058 & 0.011 & $<0.001$ & -0.072 & 0.013 & $<0.001$ \\
\hline$\varepsilon 4 \times$ time $\times$ Black & & & & 0.048 & 0.024 & $<0.05$ \\
\hline \multicolumn{7}{|l|}{ Working memory } \\
\hline$\varepsilon 4$ & -0.004 & 0.046 & 0.94 & -0.016 & 0.056 & 0.77 \\
\hline$\varepsilon 4 \times$ time & -0.037 & 0.008 & $<0.001$ & -0.047 & 0.010 & $<0.001$ \\
\hline$\varepsilon 4 \times$ time $\times$ Black & & & & 0.039 & 0.020 & $<0.05$ \\
\hline \multicolumn{7}{|l|}{ Perceptual speed } \\
\hline$\varepsilon 4$ & -0.065 & 0.050 & 0.19 & -0.021 & 0.061 & 0.73 \\
\hline$\varepsilon 4 \times$ time & -0.044 & 0.009 & $<0.001$ & -0.049 & 0.010 & $<0.001$ \\
\hline$\varepsilon 4 \times$ time $\times$ Black & & & & 0.019 & 0.020 & 0.34 \\
\hline \multicolumn{7}{|l|}{ Visuospatial ability } \\
\hline$\varepsilon 4$ & 0.015 & 0.044 & 0.73 & 0.024 & 0.054 & 0.65 \\
\hline$\varepsilon 4 \times$ time & -0.024 & 0.009 & $<0.01$ & -0.032 & 0.010 & $<0.01$ \\
\hline$\varepsilon 4 \times$ time $\times$ Black & & & & 0.032 & 0.021 & 0.13 \\
\hline
\end{tabular}

Model 1 includes the main effect of $\varepsilon 4$ on each cognitive ability and the interaction of $\varepsilon 4$ with time (in years since baseline), controlling for age, sex, education, and race. Model 2 includes the same terms as model 1 plus the 3 -way interaction of $\varepsilon 4$, time, and Black race. All models excluded persons with $\varepsilon 2 / \varepsilon 4$. 
Table 3. Relation of $A P O E \varepsilon 4$ to cognitive decline in 5 cognitive abilities, stratified by race

\begin{tabular}{|c|c|c|c|c|}
\hline $\begin{array}{l}\text { Outcome } \\
\text { measure }\end{array}$ & $\begin{array}{l}\text { Blacks } \\
\text { estimate (SE) }\end{array}$ & $\begin{array}{l}\mathrm{p} \\
\text { value }\end{array}$ & $\begin{array}{l}\text { Whites } \\
\text { estimate (SE) }\end{array}$ & $\begin{array}{l}\mathrm{p} \\
\text { value }\end{array}$ \\
\hline \multicolumn{5}{|c|}{ Episodic memory } \\
\hline$\varepsilon 4$ & $-0.072(0.016)$ & 0.23 & $-0.202(0.055)$ & $<0.001$ \\
\hline$\varepsilon 4 \times$ time & $-0.038(0.016)$ & 0.02 & $-0.065(0.012)$ & $<0.001$ \\
\hline \multicolumn{5}{|c|}{ Semantic memory } \\
\hline$\varepsilon 4$ & $0.012(0.079)$ & 0.88 & $-0.055(0.053)$ & 0.31 \\
\hline$\varepsilon 4 \times$ time & $-0.022(0.017)$ & 0.19 & $-0.073(0.013)$ & $<0.001$ \\
\hline \multicolumn{5}{|c|}{ Working memory } \\
\hline$\varepsilon 4$ & $0.017(0.086)$ & 0.84 & $-0.016(0.056)$ & $<0.77$ \\
\hline$\varepsilon 4 \times$ time & $-0.006(0.014)$ & 0.67 & $-0.049(0.010)$ & $<0.001$ \\
\hline \multicolumn{5}{|c|}{ Perceptual speed } \\
\hline$\varepsilon 4$ & $-0.167(0.078)$ & 0.03 & $-0.015(0.063)$ & 0.81 \\
\hline$\varepsilon 4 \times$ time & $-0.027(0.014)$ & 0.04 & $-0.050(0.011)$ & $<0.001$ \\
\hline \multicolumn{5}{|c|}{ Visuospatial ability } \\
\hline$\varepsilon 4$ & $-0.009(0.086)$ & 0.92 & $0.026(0.052)$ & 0.61 \\
\hline$\varepsilon 4 \times$ time & $-0.002(0.018)$ & 0.92 & $-0.033(0.012)$ & 0.002 \\
\hline
\end{tabular}

All models exclude persons with $\varepsilon 2 / \varepsilon 4$ and control for age, sex, and education.

firmed in models stratified by race for most cognitive abilities with one exception (table 3). The full model indicated no racial difference in the effect of $\varepsilon 4$ on rate of decline in visuospatial ability, but in the stratified models, the $\varepsilon 4$ allele was only related to a faster rate of decline in Whites. In sum, the $\varepsilon 4$ allele was related to a faster rate of decline in all cognitive abilities for Whites, but was only related to a faster rate of decline in episodic memory and perceptual speed in Blacks. Interestingly, the estimates associated with the effect of $\varepsilon 4$ on rate of decline in these 2 abilities were only half as large in Blacks as in Whites.

\section{Secondary Data Analyses}

Because vascular conditions have been associated with $A P O E$ and cognitive function, and there are welldocumented racial differences in vascular conditions, we repeated the original models controlling for summary indices of vascular risk factors and vascular disease. Results were essentially unchanged (data not shown). Next, we examined whether the results might be influenced by the longer follow-up times, on average, for the Rush Memory and Aging Project participants. The results were very similar to those in the full sample (data not shown).

\section{Discussion}

In two prospective cohorts of more than 1,200 community-based older Blacks and Whites free of dementia at baseline, we found in analyses that controlled for age, education, sex, and race, that the APOE $\varepsilon 4$ allele was related to a faster rate of decline in episodic memory and 4 other cognitive abilities during a mean of about 6 years of observation. Importantly, the negative effect of $\varepsilon 4$ on decline in episodic memory was similar for Blacks and Whites, although the magnitude of the relationships appeared to be a bit weaker in Blacks. Adjustment for vascular risk factors and conditions associated with cognitive impairment and typically found to be more prevalent in Blacks did not change any of the results. The results were unaffected by the longer follow-up time for the Memory and Aging Project.

$A P O E \& 4$ has been consistently shown in previous studies to be related to cognitive decline in Whites [18, 51], particularly episodic memory [25-27, 52]. Fewer studies have examined racial differences in the relation of $A P O E \varepsilon 4$ and cognitive decline $[19,20,24]$. One study found that a 5-point or greater decline in scores on the $3 \mathrm{MSE}$ over about 3 years was related to the APOE $\varepsilon 4$ genotype in Whites only [24]. By contrast, another study used the Short Portable Mental Status Questionnaire, a brief screen of cognitive function, and found that APOE $\varepsilon 4$ significantly increased the odds of cognitive decline by $59 \%$, and the effect was similar in Blacks and Whites [19]. Finally, one other study attempted a replication of a previous study [19] using a longer follow-up period and found a similar effect of $\varepsilon 4$ in Blacks and Whites [20]. Because all 3 studies used brief global measures that tend to represent fewer cognitive abilities, there is a possibility that a relatively specific effect of $A P O E$ on episodic memory has been obscured. Because the $\varepsilon 4$ allele has been shown to have a relatively selective effect on episodic memory in Whites, and some studies suggest that Blacks may have a higher risk of $\mathrm{AD}$ of which episodic memory is the hallmark feature, we hypothesized that there might be selective effects of the $\varepsilon 4$ allele on memory in Blacks. Consistent with our hypothesis, we found that the $\varepsilon 4$ allele was related to decline in episodic memory among Blacks and the effect was similar to that of Whites.

Examination of other specific cognitive abilities revealed interactions between race and $\varepsilon 4$ status only for semantic memory and working memory. These findings were confirmed in models stratified by race: there was no effect of $\varepsilon 4$ on semantic memory or working memory among Blacks, but $\varepsilon 4$ was related to a faster rate of decline 
in these 2 abilities among Whites. The negative effect of $\varepsilon 4$ on semantic and working memory among Whites is consistent with other studies $[53,54]$, but to our knowledge no study has reported findings for specific cognitive abilities among Blacks. Why the $\varepsilon 4$ allele would not have a negative effect on semantic and working memory among Blacks is uncertain. One possible explanation could be differences between participants in the two cohorts. For example, Blacks in our study tended to be younger, had a higher number of vascular risk factors than Whites, and were followed for a shorter period of time, but we adjusted for these factors in statistical models and none accounted for the difference. It is possible that other factors not examined here could differentially influence the association of $\varepsilon 4$ and cognition within the two racial groups. For example, it has been demonstrated that both lipid levels and cortisol moderate the influence of $A P O E$ on cognition $[55,56]$, and Blacks are less likely than Whites to have elevated triglycerides or low highdensity lipoprotein [57]. There is also evidence that minority populations, particularly older Blacks, experience, on average, more adverse social-environmental conditions than older Whites, including lower quality of education [58] and limited socioeconomic resources [59]. Such factors not only place older Blacks at a heightened risk for ill health, but could potentially obscure or weaken any association of the $\varepsilon 4$ allele with cognition. In fact, one recent paper using data from a population-based sample of older Blacks and Whites found that the effect of $\varepsilon 4$ on cognition was stronger in those persons living in neighborhoods with the lowest level of social disorder [60], which in this study were neighborhoods of predominantly White residents.

Finally, it is possible that the genetic architecture of Blacks and Whites differs resulting in a differential association of the $\varepsilon 4$ allele with cognition in Blacks. Given that Blacks represent an admixed population with significant genetic contributions from both African and European ancestors [61], it is possible that genetic susceptibility related to the APOE $\varepsilon 4$ allele is inconsistently expressed because there are other protective genetic factors in West African genomes that contributed to the genomes of modern Blacks. For example, a recent study reported a trend for the association between $A P O E$ genotype and dementia to be weaker in those with greater degrees of African admixture [62]. Additional longitudinal studies with diverse populations are needed to test these and other hypotheses.

The study has limitations. First, both studies are volunteer cohorts and so the full spectrum of cognitive function may not be represented in our cohorts. Second, we had fewer Blacks than Whites, potentially limiting our power to detect an effect of $A P O E$ on cognitive decline in Blacks. Third, the mean follow-up time was shorter for the black participants. Although sensitivity analyses were conducted to equate follow-up time for Blacks and Whites, and results were essentially the same, it is possible that a longer follow-up period would have yielded stronger racial differences.

Confidence in these findings is strengthened by several factors. First, composites of 2 or more individual cognitive function tests were used as outcomes, reducing the opportunity for floor and ceiling effects on single measures, and allowing us to specifically examine episodic memory and 4 other cognitive abilities rather than relying on brief global screens as in previous studies. Second, data come from 2 large, well-characterized epidemiologic cohorts with essentially identical operational methods, allowing for examination of racial differences in the association of $A P O E$ and cognitive decline. Third, all participants underwent structured annual clinical evaluations allowing for exclusion of persons with baseline dementia and robust modeling of change in cognition over the course of the study.

\section{Acknowledgements}

We are indebted to the hundreds of Illinois residents participating in the Minority Aging Research Study and the Rush Memory and Aging Project. We thank the study coordinators Charlene Gamboa, MPH and Tracey Nowakowski, the population studies research manager, Traci Colvin, MPH; data and analytic programmers, John Gibbons, MS, Greg Klein, and Woojeong Bang, MS, and the faculty and staff of the Rush Alzheimer's Disease Center. This study was supported by the National Institute on Aging grants R01 AG22018 (L.L.B.), R01 AG40039 (Z.A.), and R01 AG17917 (D.A.B.), and the Illinois Department of Public Health.

References

-1 Tzourio C, Arima H, Harrap S, Anderson C, Godin O, Woodward M, et al: APOE genotype, ethnicity, and the risk of cerebral hemorrhage. Neurology 2008;70:1322-1328.

2 Winkler K, Hoffmann MM, Krane V, Marz W, Drechsler C, Wanner C: Apolipoprotein E genotype predicts cardiovascular endpoints in dialysis patients with type 2 diabetes mellitus. Atherosclerosis 2010;208:197202

-3 Corder EH, Saunders AM, Strittmatter WJ, Schmechel DE, Gaskell PC, Small GW, et al: Gene dose of apolipoprotein E type 4 allele and the risk of Alzheimer's disease in late onset families. Science 1993;261:921-923. 
-4 Wisdom NM, Callahan JL, Hawkins KA: The effects of apolipoprotein $\mathrm{E}$ on non-impaired cognitive functioning: a meta-analysis. Neurobiol Aging 2011;32:63-74.

-5 Farrer LA, Cupples LA, Haines JL, Hyman B, Kukull WA, Mayeux R, et al: Effects of age, sex, and ethnicity on the association between apolipoprotein E genotype and Alzheimer disease. A meta-analysis. APOE and Alzheimer Disease Meta Analysis Consortium. JAMA 1997;278:1349-1356.

-6 Evans DA, Bennett DA, Wilson RS, Bienias JL, Morris MC, Scherr PA, et al: Incidence of Alzheimer disease in a biracial urban community: relation to apolipoprotein E allele status. Arch Neurol 2003;60:185-189.

7 Graff-Radford NR, Green RC, Go RC, Hutton ML, Edeki T, Bachman D, et al: Association between apolipoprotein $\mathrm{E}$ genotype and Alzheimer disease in African American subjects. Arch Neurol 2002;59:594-600.

$\checkmark 8$ Hendrie HC, Hall KS, Hui S, Unverzagt FW, Yu CE, Lahiri DK, et al: Apolipoprotein E genotypes and Alzheimer's disease in a community study of elderly African Americans. Ann Neurol 1995;37:118-120.

-9 Logue MW, Schu M, Vardarajan BN, Buros J, Green RC, Go RC, et al: A comprehensive genetic association study of Alzheimer disease in African Americans. Arch Neurol 2011;68:1569-1579.

10 Murrell JR, Price B, Lane KA, Baiyewu O, Gureje O, Ogunniyi A, et al: Association of apolipoprotein E genotype and Alzheimer disease in African Americans. Arch Neurol 2006;63:431-434.

- 11 Perry RT, Collins JS, Harrell LE, Acton RT, Go RC: Investigation of association of 13 polymorphisms in eight genes in southeastern African American Alzheimer disease patients as compared to age-matched controls. Am J Med Genet 2001;105:332-342.

12 Irie F, Fitzpatrick AL, Lopez OL, Kuller LH, Peila R, Newman AB, et al: Enhanced risk for Alzheimer disease in persons with type $2 \mathrm{di}$ abetes and APOE epsilon4: the Cardiovascular Health Study Cognition Study. Arch Neurol 2008;65:89-93.

- 13 Mount DL, Ashley AV, Lah JJ, Levey AI, Goldstein FC: Is ApoE epsilon4 associated with cognitive functioning in African Americans diagnosed with Alzheimer disease? An exploratory study. South Med J 2009;102: 890-893.

14 Tang MX, Stern Y, Marder K, Bell K, Gurland B, Lantigua R, et al: The APOE-epsilon4 allele and the risk of Alzheimer disease among African Americans, whites, and Hispanics. JAMA 1998;279:751-755.

-15 Tycko B, Lee JH, Ciappa A, Saxena A, Li CM, Feng L, et al: APOE and APOC1 promoter polymorphisms and the risk of Alzheimer disease in African American and Caribbean Hispanic individuals. Arch Neurol 2004;61: 1434-1439.
16 Maestre G, Ottman R, Stern Y, Gurland B, Chun M, Tang MX, et al: Apolipoprotein E and Alzheimer's disease: ethnic variation in genotypic risks. Ann Neurol 1995;37:254259.

17 Sahota A, Yang M, Gao S, Hui SL, Baiyewu $\mathrm{O}$, Gureje O, et al: Apolipoprotein E-associated risk for Alzheimer's disease in the African-American population is genotype dependent. Ann Neurol 1997;42:659-661.

18 Bretsky P, Guralnik JM, Launer L, Albert M, Seeman TE: The role of APOE-epsilon4 in longitudinal cognitive decline: MacArthur Studies of Successful Aging. Neurology 2003;60:1077-1081.

-19 Fillenbaum GG, Landerman LR, Blazer DG, Saunders AM, Harris TB, Launer LJ: The relationship of APOE genotype to cognitive functioning in older African-American and Caucasian community residents. J Am Geriatr Soc 2001;49:1148-1155.

20 Sawyer K, Sachs-Ericsson N, Preacher KJ, Blazer DG: Racial differences in the influence of the APOE epsilon 4 allele on cognitive decline in a sample of communitydwelling older adults. Gerontology 2009;55: $32-40$.

21 Harwood DG, Barker WW, Ownby RL, Mullan M, Duara R: Apolipoprotein E polymorphism and cognitive impairment in a bi-ethnic community-dwelling elderly sample. Alzheimer Dis Assoc Disord 2002;16:8-14.

22 Blair CK, Folsom AR, Knopman DS, Bray MS, Mosley TH, Boerwinkle E: APOE genotype and cognitive decline in a middle-aged cohort. Neurology 2005;64:268-276.

23 Borenstein AR, Mortimer JA, Wu Y, Jureidini-Webb FM, Fallin MD, Small BJ, et al: Apolipoprotein $\mathrm{E}$ and cognition in communitybased samples of African Americans and Caucasians. Ethn Dis 2006;16:9-15.

24 Kuller LH, Shemanski L, Manolio T, Haan M, Fried L, Bryan N, et al: Relationship between ApoE, MRI findings, and cognitive function in the Cardiovascular Health Study. Stroke 1998;29:388-398.

25 Adamson MM, Landy KM, Duong S, FoxBosetti S, Ashford JW, Murphy GM, et al: Apolipoprotein E epsilon4 influences on episodic recall and brain structures in aging pilots. Neurobiol Aging 2010;31:1059-1063.

26 De BS, Montesanto A, Martino C, Dato S, De RF, Bruni AC, et al: APOE polymorphism affects episodic memory among non demented elderly subjects. Exp Gerontol 2009;44:224227.

27 Mayeux R, Small SA, Tang M, Tycko B, Stern Y: Memory performance in healthy elderly without Alzheimer's disease: effects of time and apolipoprotein-E. Neurobiol Aging 2001;22:683-689.

28 Tang MX, Cross P, Andrews H, Jacobs DM, Small S, Bell K, et al: Incidence of AD in African-Americans, Caribbean Hispanics, and Caucasians in northern Manhattan. Neurology 2001;56:49-56.
29 Barnes LL, Shah RC, Aggarwal NT, Bennett DA, Schneider JA: The Minority Aging Research Study: ongoing efforts to obtain brain donation in African Americans without dementia. Curr Alzheimer Res 2012;9:736-747.

30 Bennett DA, Schneider JA, Buchman AS Barnes LL, Boyle PA, Wilson RS: Overview and findings from the Rush Memory and Aging Project. Curr Alzheimer Res 2012;9: 648-665.

31 Arvanitakis Z, Bennett DA, Wilson RS, Barnes LL: Diabetes and cognitive systems in older black and white persons. Alzheimer Dis Assoc Disord 2010;24:37-42.

- 32 McKhann G, Drachman D, Folstein M, Katzman R, Price D, Stadlan EM: Clinical diagnosis of Alzheimer's disease: report of the NINCDS-ADRDA Work Group under the auspices of Department of Health and Human Services Task Force on Alzheimer's Disease. Neurology 1984;34:939-944.

33 Wilson RS, Beckett LA, Barnes LL, Schneider JA, Bach J, Evans DA, et al: Individual differences in rates of change in cognitive abilities of older persons. Psychol Aging 2002;17:179-193.

34 Wechsler D: Wechsler Memory Scale-Revised Manual. San Antonio, Psychological Corporation, 1987.

35 Albert M, Smith LA, Scherr PA, Taylor JO, Evans DA, Funkenstein HH: Use of brief cognitive tests to identify individuals in the community with clinically diagnosed Alzheimer's disease. Int J Neurosci 1991;57:167178.

36 Wilson RS, Barnes LL, Krueger KR, Hoganson G, Bienias JL, Bennett DA: Early and late life cognitive activity and cognitive systems in old age. J Int Neuropsychol Soc 2005; 11: 400-407.

-37 Morris JC, Heyman A, Mohs RC, Hughes JP, van Belle G, Fillenbaum G, et al: The Consortium to Establish a Registry for Alzheimer's Disease (CERAD). 1. Clinical and neuropsychological assessment of Alzheimer's disease. Neurology 1989;39:1159-1165.

38 Kaplan EF, Goodglass H, Weintraub S: The Boston Naming Test. Philadelphia, Lea \& Febiger, 1983.

-39 Cooper JA, Sagar HJ: Incidental and intentional recall in Parkinson's disease: an account based on diminished attentional resources. J Clin Exp Neuropsychol 1993;15: 713-731.

40 Smith A: Symbol Digit Modalities Test Manual - Revised. Los Angeles, Western Psychological Services, 1982.

41 Ekstrom RB, French JW, Harman HH, Kermen D: Manual for Kit of Factor-Referenced Cognitive Tests. Princeton, Educational Testing Service, 1976

42 Trenerry MR, Crosson B, DeBoe J, Leber WR: Stroop Neuropsychological Screening Test Manual. Odessa, Psychological Assessment Resources, Inc, 1989. 
43 Benton AL, Sivan AB, Hamsher KD, Varney NR, Spreen O: Contributions to neuropsychological assessment, ed 2. New York, Oxford University Press, 1994.

44 Raven JC, Court JH, Raven J: Manual for Raven's Progressive Matrices and Vocabulary. Oxford, Oxford Psychologists Press, 1992.

45 Eichner JE, Kuller LH, Orchard TJ, Grandits GA, McCallum LM, Ferrell RE, et al: Relation of apolipoprotein E phenotype to myocardial infarction and mortality from coronary artery disease. Am J Cardiol 1993;71: 160-165.

-46 Wilson PW, Myers RH, Larson MG, Ordovas JM, Wolf PA, Schaefer EJ: Apolipoprotein E alleles, dyslipidemia, and coronary heart disease. The Framingham Offspring Study. JAMA 1994;272:1666-1671.

-47 Boyle PA, Wilson RS, Aggarwal NT, Arvanitakis Z, Kelly J, Bienias JL, et al: Parkinsonian signs in subjects with mild cognitive impairment. Neurology 2005;65:1901-1906.

48 Buchman AS, Boyle PA, Wilson RS, Beck TL, Kelly JF, Bennett DA: Apolipoprotein E e4 allele is associated with more rapid motor decline in older persons. Alzheimer Dis Assoc Disord 2009;23:63-69.

49 Laird NM, Ware JH: Random-effects models for longitudinal data. Biometrics 1982;38: 963-974.

50 SAS Institute Inc: SAS/STAT ${ }^{\circledR}$ User's Guide, Version 9.1.3. (8). Cary, SAS Institute Inc, 2004
51 O’Hara R, Yesavage JA, Kraemer HC, Mauricio M, Friedman LF, Murphy GM Jr: The APOE epsilon4 allele is associated with decline on delayed recall performance in community-dwelling older adults. J Am Geriatr Soc 1998;46:1493-1498.

52 Wilson RS, Schneider JA, Barnes LL, Beckett LA, Aggarwal NT, Cochran EJ, et al: The apolipoprotein $\mathrm{E} \varepsilon 4$ allele and decline in different cognitive systems over a 6-year period. Arch Neurol 2002;59:1154-1160.

53 Boyle PA, Buchman AS, Wilson RS, Kelly JF, Bennett DA: The APOE epsilon4 allele is associated with incident mild cognitive impairment among community-dwelling older persons. Neuroepidemiology 2010;34:4349.

54 Rosen VM, Sunderland T, Levy J, Harwell A, McGee L, Hammond C, et al: Apolipoprotein $\mathrm{E}$ and category fluency: evidence for reduced semantic access in healthy normal controls at risk for developing Alzheimer's disease. Neuropsychologia 2005;43:647658

55 de Frias CM, Bunce D, Wahlin A, Adolfsson $\mathrm{R}$, Sleegers K, Cruts M, et al: Cholesterol and triglycerides moderate the effect of apolipoprotein $\mathrm{E}$ on memory functioning in older adults. J Gerontol B Psychol Sci Soc Sci 2007; 62:112-118.

6 Lee BK, Glass TA, Wand GS, McAtee MJ, Bandeen-Roche K, Bolla KI, et al: Apolipoprotein e genotype, cortisol, and cognitive function in community-dwelling older adults. Am J Psychiatry 2008;165:14561464.
57 Ford ES, Giles WH, Dietz WH: Prevalence of the metabolic syndrome among US adults: findings from the third National Health and Nutrition Examination Survey. JAMA 2002; 287:356-359.

58 Manly JJ: Deconstructing race and ethnicity: implications for measurement of health outcomes. Med Care 2006;44:S10-S16.

59 Wilson RS, Scherr PA, Bienias JL, Mendes de Leon CF, Everson-Rose SA, Bennett DA, et al: Socioeconomic characteristics of the community in childhood and cognition in old age. Exp Aging Res 2005;31:393-407.

60 Boardman JD, Barnes LL, Wilson RS, Evans DA, Mendes de Leon CF: Social disorder, APOE-E4 genotype, and change in cognitive function among older adults living in Chicago. Soc Sci Med 2012;74:1584-1590.

-61 Chakraborty R, Kamboh MI, Ferrell RE: 'Unique' alleles in admixed populations: a strategy for determining 'hereditary' population differences of disease frequencies. Ethn Dis 1991;1:245-256.

62 Teruel BM, Rodriguez JJ, McKeigue P, Mesa TT, Fuentes E, Cepero AA, et al: Interactions between genetic admixture, ethnic identity, APOE genotype and dementia prevalence in an admixed Cuban sample; a cross-sectional population survey and nested case-control study. BMC Med Genet 2011;12:43. 